\title{
Mutation Induction in the Cyanobacterium Gloeocapsa alpicola
}

\author{
By JOAN A. M. LAMBERT, EDWIN WILLIAMS, \\ PHILIP A. O'BRIEN AND JAMES A. HOUGHTON* \\ Department of Microbiology, University College, Galway, Ireland
}

(Received 12 March 1980)

The lethal and mutagenic effects of ultraviolet light (u.v.), ethyl methanesulphonate (EMS), methyl methanesulphonate (MMS), $N$-methyl- $N^{\prime}$-nitro- $N$-nitrosoguanidine (MNNG) and mitomycin C on the unicellular cyanobacterium Gloeocapsa alpicola have been investigated. Mitomycin $\mathrm{C}$ and EMS did not significantly increase the frequency of streptomycin-resistant mutants above the spontaneous level. MNNG and MMS produced increases of 10 to 30 times the spontaneous frequency. Contrary to previous reports on mutation induction in cyanobacteria, u.v. was the most effective mutagen, increasing the spontaneous mutation frequency 4000 -fold. However, since photoreactivating light eliminated most of this mutagenic response it was necessary to rigorously exclude light of wavelengths $<550 \mathrm{~nm}$ during post-irradiation growth. Caffeine failed to increase the mutation frequency of u.v.irradiated cultures, but cells were more sensitive to u.v. killing in the presence of caffeine.

\section{INTRODUCTION}

Genetic studies on cyanobacteria have been restricted to a few species, most of which are difficult to manipulate, either because they are filamentous or because they lack reproducible growth on agar-containing media (Ladha \& Kumar, 1978). The most widely used unicellular species is Anacystis nidulans which, although showing high plating efficiency, has the disadvantage of not being a nitrogen-fixing species (Stanier \& Cohen-Bazire, 1977). Gloeocapsa alpicola would appear to provide a suitable alternative for genetic studies since it is unicellular, has a high plating efficiency and some strains are capable of fixing atmospheric nitrogen. It also has a high frequency of genetic transformation (Devilly, 1975; Devilly \& Houghton, 1977). However, one of the major problems that has restricted the development of genetic studies in the cyanobacteria has been the difficulties encountered in the isolation of suitable mutant strains. Mutation induction using antibiotic resistance, auxotrophy, pigmentation changes, temperature sensitivity, filamentation or cyanophage resistance as markers, has been demonstrated in Anacystis nidulans (Herdman et al., 1973), Anabaena doliolum (Singh \& Singh, 1964), Phormidium mucicola (Srivastava, 1969), Agmenellum quadruplicatum (Ingram et al., 1972), Synechocystis aquatilis (Zhevner \& Shestakov, 1972), Cylindrospermum majus (Singh \& Sinha, 1965), Nostoc linckia (Singh \& Tiwari, 1969), Plectonema boryanum (Padan \& Shilo, 1969) and Synechococcus cedrorum (Kaney, 1973). A wide range of mutagens has been used to induce mutations in cyanobacteria (Delaney et al., 1976). However, many authors have failed to comment on the efficiency of mutagenesis and comparisons are complicated by the lack of standardization of techniques. In general, $N$-methyl- $N^{\prime}$-nitro- $N$-nitrosoguanidine, nitrosoamines and nitrosomethyl urea are considered to be efficient mutagens; whereas methyl methanesulphonate, ethyl methanesulphonate and diethyl sulphate are considered to be less effective (Shestakov \& Jevner, 
1968). X-rays, mitomycin $\mathrm{C}$, hydroxylamine, acridine orange and ultraviolet light are considered to be poor mutagens for cyanobacteria (Shestakov, 1972).

In the present study, the effect of a variety of mutagens on survival and on mutation to streptomycin resistance in Gloeocapsa alpicola has been examined. Efficiencies of mutagenesis and optimal conditions for mutation have been determined.

\section{METHODS}

Organisms. Gloeocapsa alpicola (Lyngbye) Bornet, a unicellular cyanobacterium which produces nitrogenase, was obtained from the Culture Collection of Algae and Protozoa, Cambridge (collection no. 1430/1). Escherichia coli strain AB1157 was obtained from the E. coli Genetic Stock Center, Yale University School of Medicine, New Haven, Conn., U.S.A.

Media and growth conditions. The medium for G. alpicola was a modification of that described by Allen (1968). Liquid growth medium contained ( $\mathrm{g} \mathrm{l}^{-1}$ in deionized distilled water): $\mathrm{NaNO}_{3}, 1 \cdot 5 ; \mathrm{K}_{2} \mathrm{HPO}_{4}, 3 \cdot 9 \times$ $10^{-2} ; \mathrm{MgSO}_{4} .7 \mathrm{H}_{2} \mathrm{O}, 7.5 \times 10^{-2} ; \mathrm{CaCl}_{2}, 3.6 \times 10^{-2}$; citric acid, $1.2 \times 10^{-2}$; ferric citrate, $6.0 \times 10^{-3} ; \mathrm{H}_{3} \mathrm{PO}_{4}$, $2.9 \times 10^{-3} ; \mathrm{MnCl}_{2}, 1.8 \times 10^{-3} ; \mathrm{ZnSO}_{4} .7 \mathrm{H}_{2} \mathrm{O}, 2.22 \times 10^{-4} ; \mathrm{Na}_{2} \mathrm{MoO}_{4} .2 \mathrm{H}_{2} \mathrm{O}, 3.9 \times 10^{-4} ; \mathrm{CuSO}_{4} .5 \mathrm{H}_{2} \mathrm{O}$, $7.8 \times 10^{-5} ; \mathrm{Co}\left(\mathrm{NO}_{3}\right)_{2} .6 \mathrm{H}_{2} \mathrm{O}, 5.0 \times 10^{-5}$. Sodium silicate $\left(0.58 \mathrm{~g}^{-1}\right)$ and EDTA $\left(10^{-3} \mathrm{~g}^{-1}\right)$ were added and the mixture was heated to boiling. After cooling, the $\mathrm{pH}$ was adjusted to 5.5 and the medium was sterilized at $121{ }^{\circ} \mathrm{C}$ for $15 \mathrm{~min}$. After cooling, filter-sterilized $\mathrm{Na}_{2} \mathrm{CO}_{3}$ was added to a final concentration of $2.0 \times 10^{-2}$ $\mathrm{g}^{-1}$ giving a final $\mathrm{pH}$ of 8.0 to 8.5 . Flasks $(500 \mathrm{ml})$ containing $100 \mathrm{ml}$ of medium were inoculated with single colonies of G. alpicola or a $1 \%(\mathrm{v} / \mathrm{v})$ inoculum of an exponentially growing culture and incubated in a Gallenkamp illuminated orbital incubator at $30 \pm 1{ }^{\circ} \mathrm{C}, 120$ oscillations $\mathrm{min}^{-1}$ and under constant illumination with white fluorescent light at $2000 \mathrm{~lx}$. Solid medium was prepared by mixing sterile, double-strength salts medium with an equal volume of sterile Difco Bacto-agar $\left(3.6 \%\right.$, w/v, in distilled water) at $45^{\circ} \mathrm{C}$. After rapid mixing the medium was poured into plastic Petri dishes and the plates were dried at $60^{\circ} \mathrm{C}$ for $10 \mathrm{~min}$.

Viable counts were determined by diluting liquid cultures of $G$. alpicola in single salts medium and spreading $0.1 \mathrm{ml}$ appropriate dilutions on dried plates. The plates were incubated at $30 \pm 1{ }^{\circ} \mathrm{C}, 50 \%$ relative humidity and illuminated with gold-yellow light (Thorn International; $\lambda 550$ to $700 \mathrm{~nm}$ ) at an intensity of $2000 \mathrm{~lx}$. Colonies were counted after incubation for 10 to $14 \mathrm{~d}$.

The selective media for $G$. alpicola contained $2 \mu \mathrm{g}$ streptomycin sulphate $\mathrm{ml}^{-1}$; the minimum concentration of streptomycin to which wild-type G. alpicola is sensitive is $0.5 \mu \mathrm{g} \mathrm{ml}^{-1}$. Mutant counts were made after incubation for $21 \mathrm{~d}$.

Escherichia coli was grown in Oxoid nutrient broth. Non-selective agar for the estimation of viable counts was made by adding $15 \mathrm{~g}$ Oxoid no. 1 agar $\mathrm{l}^{-1}$ to broth. Plates were incubated at $37^{\circ} \mathrm{C}$ and colonies were counted after $24 \mathrm{~h}$.

Mutagenic treatments. (i) Ultraviolet light (u.v.). Escherichia coli was washed and resuspended in phosphate buffer, $\mathrm{pH} 7 \cdot 0$, prior to irradiation. Gloeocapsa alpicola was irradiated in single salts medium. Cultures at a density of $10^{8}$ cells $\mathrm{ml}^{-1}$ were exposed to $254 \mathrm{~nm}$ u.v. from a mercury discharge lamp (Griffin \& George) at room temperature; the incident dose rate was $0 \cdot 19 \mathrm{~J} \mathrm{~m}^{-2} \mathrm{~s}^{-1}$. The suspensions were magnetically stirred throughout the irradiation period. Irradiations and all subsequent manipulations were carried out under yellow light to prevent photoreactivation. Where indicated, u.v.-irradiated cultures were held in buffer containing $0.2 \%(\mathrm{w} / \mathrm{v})$ caffeine for $24 \mathrm{~h}$ before washing and plating or diluting in broth. Irradiated $G$. alpicola was plated and incubated with either gold-yellow or white light at $2000 \mathrm{~lx}$. Where indicated, u.v.irradiated cultures were exposed to blue light (Thorn International; $\lambda 350$ to $550 \mathrm{~nm}$ ) at an intensity of 2000 lx. To ensure maximum photoreactivation, cultures were exposed to blue light for $90 \mathrm{~min}$ (Williams et al., 1979). (ii) Ethyl methanesulphonate (EMS) and methyl methanesulphonate (MMS). EMS and MMS were added to exponentially growing cultures incubated under normal growth conditions. Where necessary, the mutagens were diluted either in $0.1 \mathrm{M}$-phosphate buffer, $\mathrm{pH} \mathrm{7.0} \mathrm{(for} E$. coli) or single salts medium (for $G$. alpicola) prior to addition to cultures. (iii) $N$-Methyl- $N^{\prime}$-nitro- $N$-nitrosoguanidine (MNNG). A freshly prepared, filter-sterilized solution was added to exponentially growing cultures incubated under normal growth conditions. (iv) Mitomycin C. Mitomycin C (Sigma) was dissolved in 0.1 M-phosphate buffer, pH 7.0 (for E. coli) or single salts medium (for G. alpicola) and added to exponentially growing cultures incubated under normal growth conditions.

Post-treatment of cultures. After incubation with chemical mutagens for the appropriate time, cultures were immediately diluted 10 -fold in warm growth medium, centrifuged in a Microfuge (Beckman), washed and resuspended in growth medium. The time taken to remove the mutagens by centrifugation was less than 2 min.

Estimation of induced mutation. Mutagen-treated cultures were diluted and spread on non-selective plates 


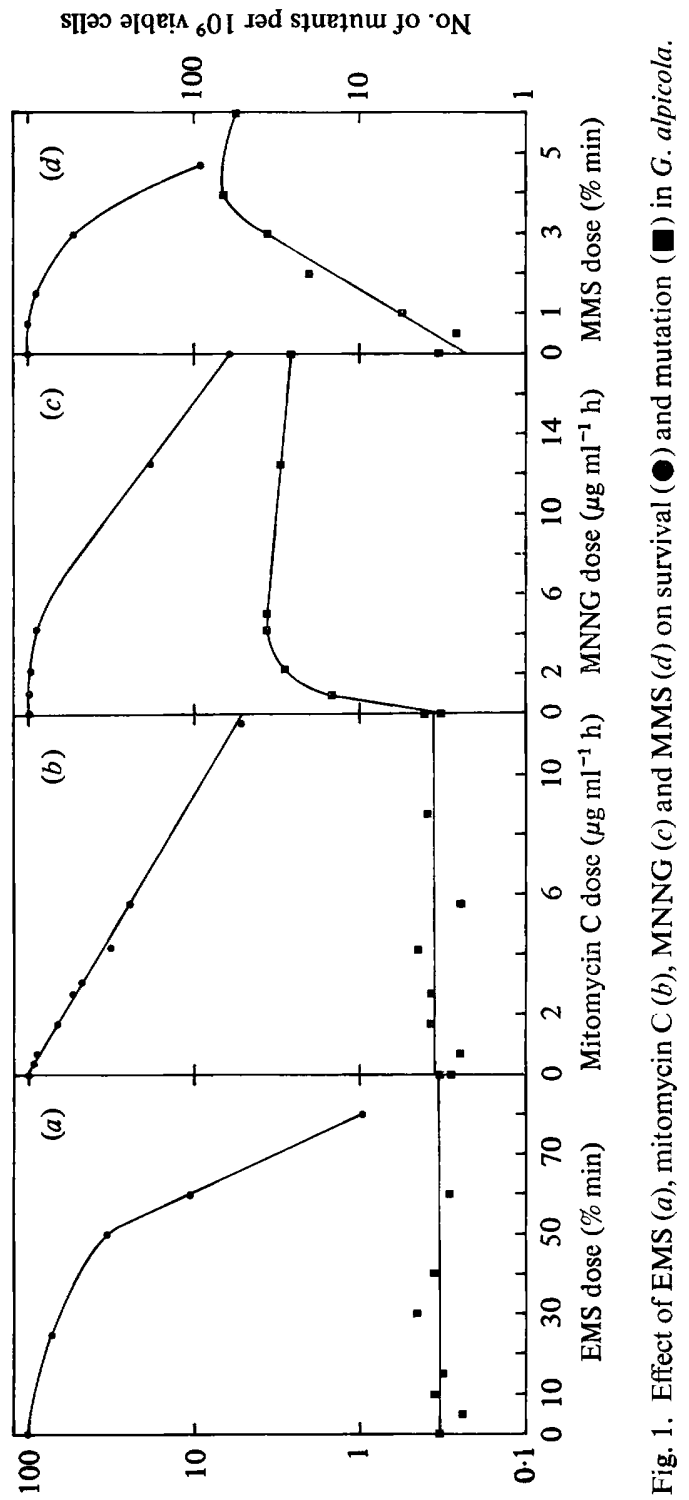

(\%) [exịuns 


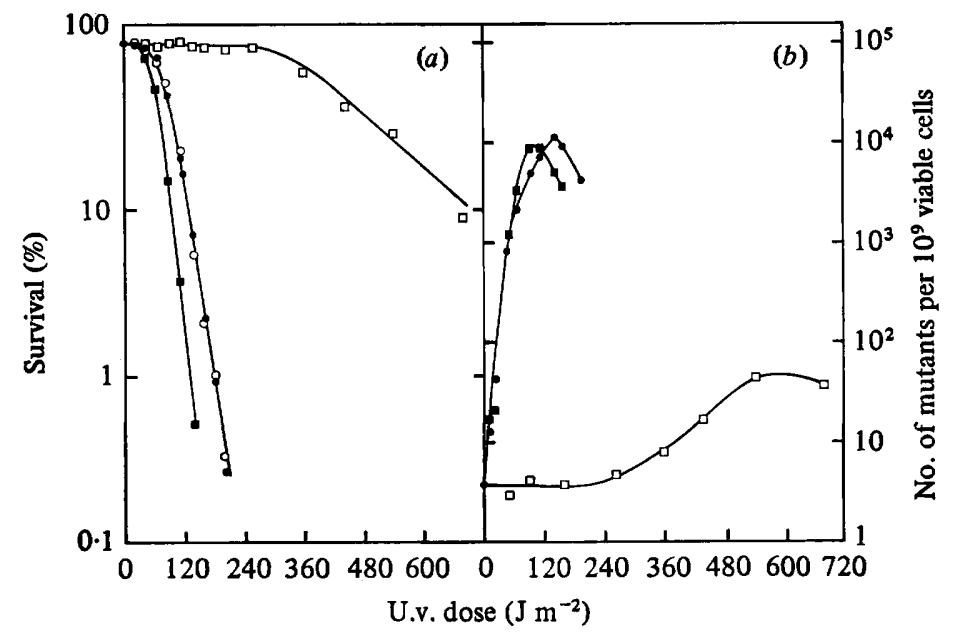

Fig. 2. Effect of u.v. on survival (a) and mutation (b) in G. alpicola showing the influence of illumination and caffeine. Post-irradiation treatment of the cells: $\square$, white light illumination, no caffeine; 0 , gold light illumination, no caffeine; $O$, gold light illumination, $0.015 \%$ caffeine; $\mathbf{\square}$, gold light illumination, $0 \cdot 20 \%$ caffeine.

to estimate survival. Cultures were also diluted 100 fold into the appropriate broth and incubated under normal growth conditions until fully grown. These cultures were concentrated 10 -fold, concentrated 30 -fold, plated directly or diluted and plated on selective agar medium to estimate the number of mutants and were also diluted and spread on non-selective agar to estimate the number of cells plated. Untreated cultures were used as controls. The mutation frequency was expressed as the number of mutants per $10^{9}$ viable cells plated.

Effect of caffeine on viability of G. alpicola. Exponentially growing cultures were diluted and plated on agar medium containing a range of concentrations of caffeine. Plates were incubated as previously described.

\section{RESULTS AND DISCUSSION}

The isolation of mutants resistant to antibiotics, amino acids and amino acid analogues is a reliable indication of mutation in cyanobacteria (Delaney et al., 1976). In the present study, resistance to $2 \mu \mathrm{g}$ streptomycin $\mathrm{ml}^{-1}$ was used as a marker. A streptomycin concentration of $100 \mu \mathrm{g} \mathrm{ml}^{-1}$ was required to inhibit these mutants compared with $0.5 \mu \mathrm{g} \mathrm{ml}^{-1}$ for the wild-type strain. The effects of EMS, mitomycin C, MNNG, MMS and u.v. on survival and mutation in G. alpicola are illustrated in Figs 1 and 2. The results presented are an average of at least three independent experiments and each point represents at least 150 mutant colonies. At frequencies close to the spontaneous level, cells were concentrated 10- or 30fold. However, at these low frequencies mutant counts varied between experiments. The spontaneous frequency shown is an average value obtained over all experiments. All other frequencies have been corrected for variation in the spontaneous frequency between experiments. The development of resistance to streptomycin was a stable character, resistance being maintained for more than 10 subcultures in the absence of challenge.

EMS and mitomycin $\mathrm{C}$ failed to increase significantly the frequency of mutants above the spontaneous frequency, although at these low frequencies mutant counts were variable and small increases in frequency were probably undetectable (Fig. $1 a, b$ ). Although EMS is considered to induce mutations independently of the DNA repair mechanisms (Ishii \& Kondo, 1975), it is non-mutagenic for the rad-6 mutant of Saccharomyces cerevisiae (Bridges, 1976) and for obligate methane-oxidizing bacteria (Williams \& Shimmin, 1978) and is only marginally mutagenic for Micrococcus radiodurans (Sweet \& Moseley, 1974, 1976). The repair-dependent mutagen, mitomycin C, upon reduction in the cell, produces a mixture of mono-adducts and thermostable cross-links between complementary DNA 
Table 1. Effects of mutagens on the survival of Gloeocapsa alpicola and Escherichia coli AB1157

$\mathrm{D}_{37}$ survival values*

Treatment

U.v. + yellow light

U.v. + white light

U.v. + yellow light $+0.2 \%$ caffeine

MMS

MNNG

EMS

Mitomycin C

\begin{tabular}{|c|c|c|c|}
\hline \multicolumn{4}{|c|}{$\mathrm{D}_{37}$ survival values* } \\
\hline & & & G. alpicola \\
\hline Units & G. alpicola & E. coli & E. coli \\
\hline $\mathrm{J} \mathrm{m}^{-2}$ & 99 & 130 & $0 \cdot 76$ \\
\hline $\mathrm{J} \mathrm{m}^{-2}$ & 480 & 220 & $2 \cdot 18$ \\
\hline $\mathrm{J} \mathrm{m}^{-2}$ & 75 & 124 & 0.61 \\
\hline$\% \min$ & $3 \cdot 5$ & $11 \cdot 8$ & 0.29 \\
\hline$\mu \mathrm{g} \mathrm{ml}^{-1} \mathrm{~h}$ & 9.5 & 35.0 & 0.27 \\
\hline$\% \min$ & $47 \cdot 2$ & 134.0 & 0.35 \\
\hline$\mu \mathrm{g} \mathrm{ml}^{-1} \mathrm{~h}$ & $4 \cdot 0$ & $2 \cdot 0$ & 2.00 \\
\hline
\end{tabular}

* $D_{37}$ is the dose of mutagen required to reduce the viability to $37 \%$ of its original value and represents the average dose required to inactivate a cell.

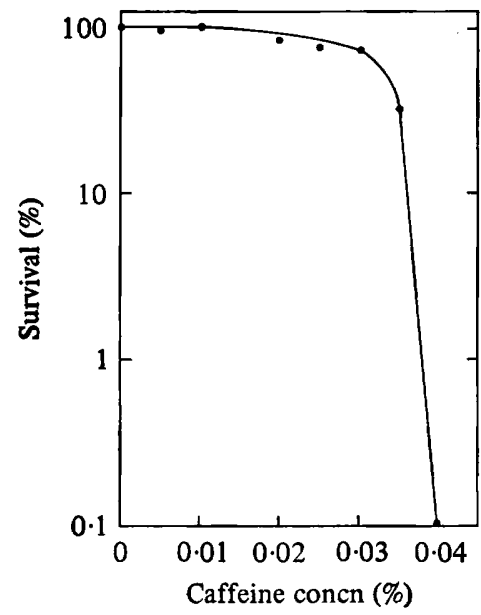

Fig. 3. Effect of caffeine on the colony-forming ability of unirradiated G. alpicola.

strands. Repair of these lesions may give rise to mutational events (Kimball, 1978; Hanawalt et al., 1979). The absence of mutation induction and the shoulderless survival curve (Fig. 1 b) may indicate that $G$. alpicola is unable to repair DNA cross-links.

MNNG was moderately mutagenic for $G$. alpicola and, as with many heterotrophic bacteria, maximum mutagenesis was found at high levels of survival (Fig. 1c). However, the 10 -fold increase in mutation frequency does not justify its adoption as an efficient mutagen for cyanobacteria. MMS increased the frequency of streptomycin-resistant mutants 30fold (Fig. 1d). Gloeocapsa alpicola was approximately three times more sensitive to the lethal effects of EMS, MMS and MNNG than was E. coli (Table 1).

Contrary to previous reports which have indicated that u.v. is a very poor mutagen, only marginally increasing mutation frequencies in cyanobacteria, this study has shown that u.v. is a most efficient mutagen for $G$. alpicola, increasing the frequency of streptomycinresistant mutants by as much as 4000 times the spontaneous frequency (Fig. 2). However, previous studies have measured u.v.-induced mutation after incubation in the presence of white light illumination, whereas in this study, the mutants were scored after incubation in the presence of non-photoreactivating yellow light. Illumination with white light increased survival and reduced the yield of mutants in u.v.-irradiated G. alpicola (Fig. 2). An extremely efficient mechanism of photoreactivation has been demonstrated in G. alpicola (Williams et 
al., 1979) and many other cyanobacteria (Ladha \& Kumar, 1978). Photoreactivation in $E$. coli is an error-free mechanism which increases survival and decreases mutagenesis in u.v.irradiated cultures by monomerizing cyclobutane pyrimidine dimers in situ (Witkin, 1976; Hanawalt et al., 1979).

Caffeine is fairly toxic to G. alpicola when incorporated into the growth medium (Fig. 3). A concentration of $0.015 \%$, just below the toxic threshold, had no effect on the survival of u.v.-irradiated G. alpicola (Fig. 2), or on the loss of photoreversibility of lethal u.v. damage (E. Williams, unpublished results) and presumably does not inhibit dark repair processes. A higher concentration $(0.2 \%)$, although extremely toxic to growing cells of unirradiated $G$. alpicola, had no effect on the viability of non-growing cultures held for periods up to $80 \mathrm{~h}$ before washing and plating (Williams et al., 1979). This concentration of caffeine inhibited loss of photoreversibility of lethal u.v. damage (Williams et al., 1979) and reduced the viability of irradiated cultures (Fig. 2), presumably by inhibiting pre-replication dark repair events. However, $0.2 \%$ caffeine failed to increase the yield of u.v.-induced mutants.

In conclusion, provided that light of wavelengths $<550 \mathrm{~nm}$ is rigorously excluded during post-irradiation manipulation and growth, u.v. is a very efficient mutagen for G. alpicola. MMS and MNNG provide reasonable alternatives.

We wish to acknowledge the technical assistance of Miss Mary Barry. The work was financed in part by Euratom under its Biology and Health Protection Programme, Contract no. 127174-1 BIO EIR.

\section{REFERENCES}

AlleN, M. M. (1968). Simple conditions for growth of unicellular blue-green algae on plates. Journal of Phycology 4, 1-4.

Bridges, B. A. (1976). Mutation induction. In Second International Symposium on the Genetics of Industrial Microorganisms, pp. 7-14. Edited by K. D. Macdonald. London: Academic Press.

Delaney, S. F., Herdman, M. \& Carr, N. G. (1976). Genetics of blue-green algae. In Genetics of Algae, pp. 7-29. Edited by R. A. Lewin. Oxford: Blackwell Scientific Publications.

DeVILLy, C. I. (1975). A study of the growth and genetics of Gloeocapsa alpicola. Ph.D. thesis, National University of Ireland.

Devilly, C. I. \& Houghton, J. A. (1977). A study of genetic transformation in Gloeocapsa alpicola. Journal of General Microbiology 98, 277-280.

Hanawalt, P. C., Cooper, P. K., Ganesan, A. K. \& SMITH, C. A. (1979). DNA repair in bacteria and mammalian cellș. Annual Review of Biochemistry 48, 783-836.

Herdman, M., Delaney, S. F. \& Carr, N. G. (1973). A new medium for the isolation and growth of auxotrophic mutants of the blue-green alga Anacystis nidulans. Journal of General Microbiology 79, 233-237.

Ingram, L. O., Pierson, D., Kane, J. F. \& Van BAALEN, C. (1972). Documentation of auxotrophic mutation in blue-green bacteria: characterization of a tryptophan auxotroph in Agmenellum quadruplicatum. Journal of Bacteriology 111, 112-118.

IsHII, Y. \& Kondo, S. (1975). Comparative analysis of deletion and base-change mutabilities of Escherichia coli B strains differing in DNA repair capacity (wild-type, $u v r A^{-}$, pol $A^{-}, \operatorname{rec} A^{-}$) by various mutagens. Mutation Research 27, 27-44.
KANEY, A. R. (1973). Enzymatic characterization of a phenylalanine auxotroph of the blue-green bacterium Synechococcus cedrorum. Archiv für Mikrobiologie 92, 139-142.

Kimball, R. F. (1978). The relation of repair phenomenon to mutation induction in bacteria. Mutation Research 55, 85-120.

LADHA, J. K. \& KuMAR, H. D. (1978). Genetics of blue-green algae. Biological Reviews 53, 355-386.

PADAN, E. \& ShILO, M. (1969). Short-trichome mutant of Plectonema boryanum. Journal of Bacterio$\log y$ 97, 975-976.

ShESTAKov, S. V. (1972). Mutagenesis and repair systems in unicellular blue-green algae. In Taxonomy and Biology of Blue-Green Algae, pp. 262-263. Edited by T. V. Desikachary. Madras: University of Madras.

Shestakov, S. V. \& JeVner, V. D. (1968). Study of mutagenesis in the blue-green alga Anacystis nidulans. Proceedings of the XII International Congress of Genetics 1, 84.

SiNGH, R. N. \& SiNGH, H. N. (1964). Ultraviolet induced mutants of blue-green algae. II. Anabaena doliolum Bharadwaja. Archiv für Mikrobiologie 48, 118-121.

Singh, R. N. \& SinHA, R. (1965). Genetic recombination in the blue-green alga Cylindrospermum majus Keutz. Nature, London 207, 782-783.

Singh, R. N. \& TrwarI, D. N. (1969). Induction by ultraviolet irradiation of mutation in the bluegreen alga Nostoc linckia (Roth) Born. et Flah. Nature, London 221, 62-64.

Srivastava, B. S. (1969). Ultraviolet induced mutations to growth factor requirement and penicillin resistance in a blue-green alga. Archiv für Mikrobiologie 66, 234-238. 
Stanier, R. Y. \& Cohen-Bazire, G. (1977). Phototrophic prokaryotes: the cyanobacteria. Annual Review of Microbiology 31, 225-275.

Sweet, D. M. \& Moseley, B. E. B. (1974). Accurate repair of ultraviolet induced damage in Micrococcus radiodurans. Mutation Research 23, 311318.

Sweet, D. M. \& Moseley, B. E. B. (1976). Resistance of Micrococcus radiodurans to killing and mutation by agents which damage DNA. Mutation Research 34, 175-186.

Williams, E. \& Shimmin, M. A. (1978). Radiationinduced filamentation in obligate methylotrophs. FEMS Microbiology Letters 4, 137-141.
Williams, E., Lambert, J., O'Brien, P. A. \& Houghton, J. A. (1979). Evidence for dark repair of ultraviolet light damage in the blue-green alga Gloeocapsa alpicola. Photochemistry and Photobiology 29, 543-547.

WITKIN, E. M. (1976). Ultraviolet mutagenesis and inducible DNA repair in Escherichia coli. Bacteriological Reviews 40, 869-907.

ZheVNer, V. D. \& Shestakov, S. V. (1972). Studies on ultraviolet sensitive mutants of the blue-green alga Synechocystis aquatilis Sanv. Archiv für Mikrobiologie 86, 349-360. 